\title{
WestVirginiaUniversity
}

THE RESEARCH REPOSITORY @ WVU

Graduate Theses, Dissertations, and Problem Reports

2014

\section{Effects of long-term phonological knowledge on learning new words}

Elizabeth S. Smith

West Virginia University

Follow this and additional works at: https://researchrepository.wvu.edu/etd

\section{Recommended Citation}

Smith, Elizabeth S., "Effects of long-term phonological knowledge on learning new words" (2014).

Graduate Theses, Dissertations, and Problem Reports. 543.

https://researchrepository.wvu.edu/etd/543

This Thesis is protected by copyright and/or related rights. It has been brought to you by the The Research Repository @ WVU with permission from the rights-holder(s). You are free to use this Thesis in any way that is permitted by the copyright and related rights legislation that applies to your use. For other uses you must obtain permission from the rights-holder(s) directly, unless additional rights are indicated by a Creative Commons license in the record and/ or on the work itself. This Thesis has been accepted for inclusion in WVU Graduate Theses, Dissertations, and Problem Reports collection by an authorized administrator of The Research Repository @ WVU. For more information, please contact researchrepository@mail.wvu.edu. 


\title{
EFFECTS OF LONG-TERM PHONOLOGICAL KNOWLEDGE ON LEARNING NEW WORDS
}

\author{
Elizabeth S. Smith
}

Thesis submitted to the College of Education and Human Services at West Virginia University in partial fulfillment of the requirements for the degree of

Master of Science in Communication Sciences and Disorders

Michelle W. Moore, Ph.D., Chair

Dennis Ruscello, Ph.D.

Norman Lass, Ph.D.

Jeremy Donai, Ph.D.

Department of Communication Sciences and Disorders

Morgantown, West Virginia

2014 


\title{
ABSTRACT \\ Effects of long-term phonological knowledge on learning new words
}

Elizabeth S. Smith

\begin{abstract}
Language learning has been attributed to multiple aspects of cognition; two primary components are phonological short-term memory and long-term knowledge. Short-term memory is responsible for the temporary storage and rehearsal of new information, and long-term knowledge is responsible for storing information gained throughout the lifetime. If one or both of these areas are found to be deficient, language impairments may be present. Although the role of short-term memory and long-term knowledge has been identified as important, their relative contributions to different language processes are not completely understood. This study used a novel within-subjects approach to examine the impact of long-term phonological knowledge (operationalized by contrasting early-developing and late-developing phonemes) on learning new words. Thirty students from West Virginia University completed a nonword repetition task and a word learning paradigm both containing nonwords comprising of only early- or only laterdeveloping phonemes. Results revealed a significant difference of phoneme type in both the nonword repetition and word learning tasks, with lower accuracies for nonwords containing only later-developing phonemes. This study shows how the relative quality of long-term phonological knowledge can impact word learning abilities even for typical individuals, and it has implications for the theoretical constructs of language development and language impairment.
\end{abstract}




\section{Table of Contents}

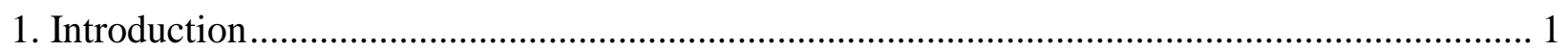

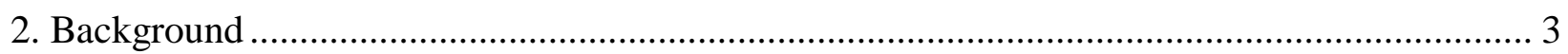

2.1 Word knowledge in typical development and language impairment ............................... 3

2.2 Long-term memory, short-term memory, and word learning .......................................... 8

2.3 Lexicality effects in nonword repetition..................................................................... 16

2.4 Rationale of current project ..................................................................................... 18

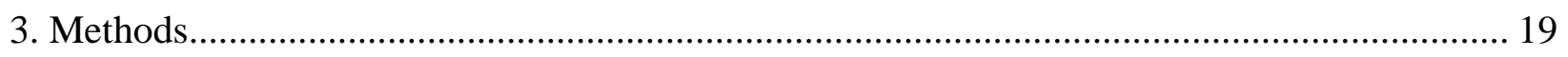

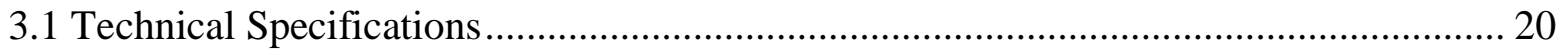

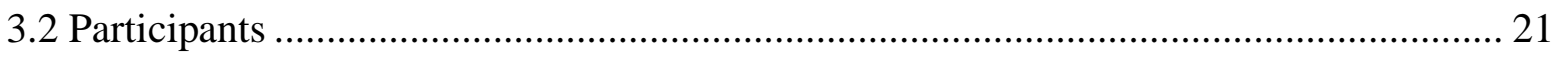

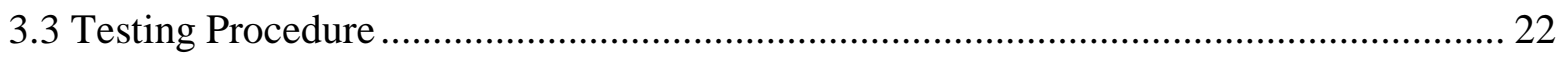

3.4 Baseline Measurements ............................................................................................ 23

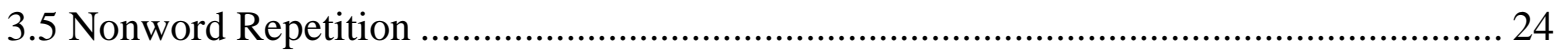

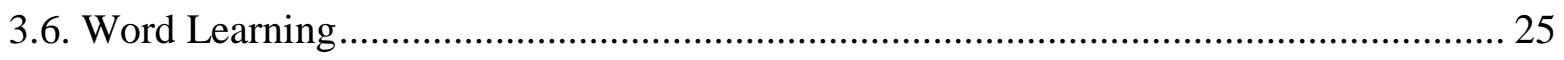

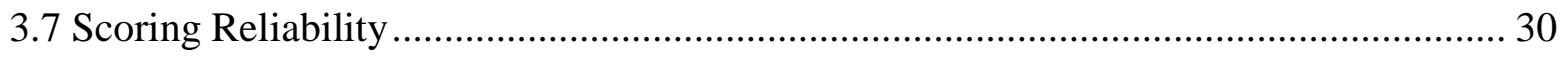

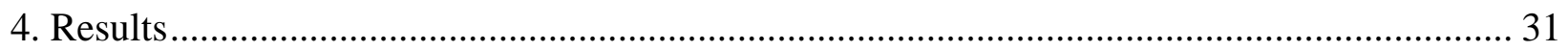

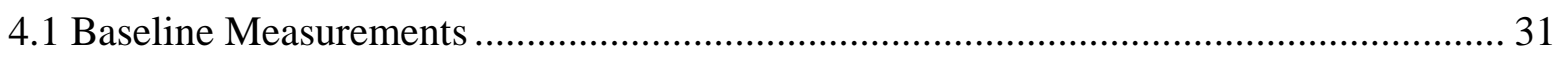

4.2 Nonword repetition ............................................................................................ 32

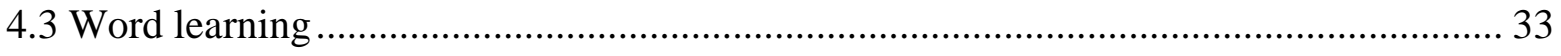

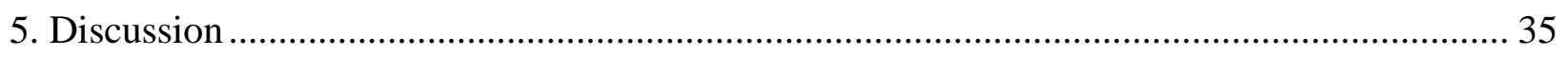

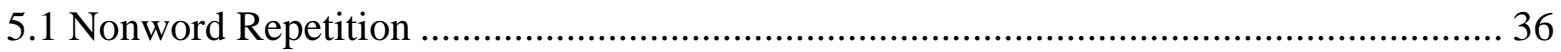

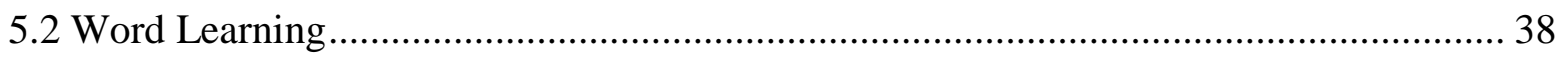

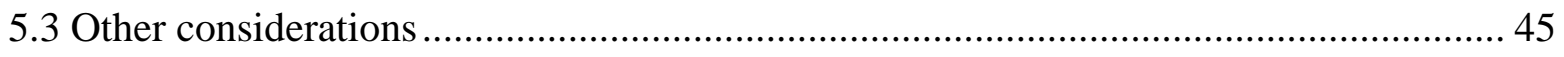

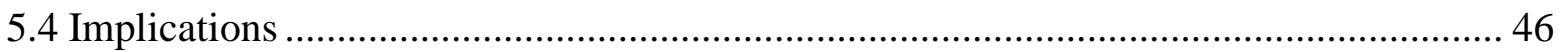

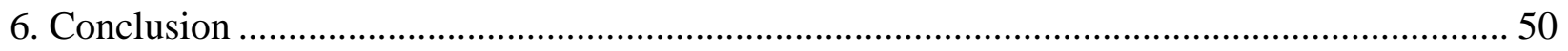

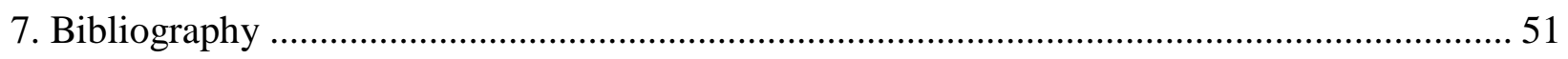




\section{Introduction}

Vocabulary acquisition is a critical component to developing typical language which, in turn, is a cornerstone for social and academic maturity. Children with limited vocabulary or an impaired ability to acquire vocabulary are at risk for poor performance in school and poor reading and writing ability (Dickinson \& Porche, 2011; Muter, Hulme, Snowling, \& Stevenson, 2004; Walker, Greenwood, Hart \& Carta, 1994). Such consequences warrant the study of the mechanisms involved in learning new words so that researchers and clinicians can establish effective diagnostic and intervention programs for children with vocabulary and language impairments.

One aspect of vocabulary acquisition, or word learning, which has been studied extensively, is the interactive relationship with long-term knowledge and short-term memory. Word learning occurs through the repeated exposure to novel word-concept pairings (Gathercole, 2006). Increased experience with a word strengthens the mental representation of that word so it can be used more effectively for language comprehension and production (Dell, 1986, 1988; Gathercole, 2006; Levelt, 2001; Levelt, Roelofs, \& Meyer, 1999; Perfetti \& Hart, 2002). It is hypothesized that verbal short-term memory serves as one mechanism for transferring novel lexical information into long-term knowledge. As part of this verbal short-term memory, Baddeley, Gathercole, and Papagano (1998) describe a phonological loop that "is specialized for the retention of verbal information over short periods of time; it comprises both a phonological store, which holds information in phonological form, and a rehearsal process, which serves to maintain decaying representations in the phonological store (p. 158)". The rehearsal process of short-term memory helps to keep information readily available for immediate use, as well as 
strengthen the long-term mental representation within long-term memory so that the information can be used at a later time (Baddeley et al., 1998; Baddeley \& Hitch, 2000).

Long-term memory refers to the storage of information gained throughout the lifetime, including the knowledge necessary for language comprehension and production. An area of focus for this study is vocabulary. Vocabulary knowledge within the lexicon, or the mental dictionary of language, consists of lexical representations that are formed by the individual's phonological, articulatory, orthographic, semantic, and syntactic knowledge of the word (Maillart, Schelstraete, \& Hupet, 2004; Perfetti \& Hart, 2002; Snowling \& Hulme, 1994). The quality of mental representations greatly affects how individuals understand and use words. For example, detailed phonological representations, the stored knowledge of individual sounds and the rules for combining them (Anthony, Williams, Aghara, Dunkelberger, Novak, \& Mukherjee, 2010; Claessen \& Leitao, 2012; Gillon, 2002; Hester \& Hodson, 2004; Wolf, Vellutino, \& Berko Gleason, 1998), are important for distinguishing between similar sounding lexical items when retrieving words from the lexicon in language production (Claessen \& Leitao, 2012; Fowler, 1991). If phonological representations are weak or degraded within the lexicon, segmenting and manipulating representations become more difficult and may result in decreased use (Claessen $\&$ Leitao, 2012; Elbro, Borstrom, \& Petersen, 1998). Weaker representations within the lexicon can be easily confused and may be more susceptible to mispronunciation; they may not be chosen for use because they are more susceptible to competition and they are accessed less efficiently than stronger representations (Dell, 1986, 1988; Levelt, 2001; Levelt et al., 1999).

The purpose of this study is to examine how the varied quality of phonological knowledge affects word learning using a novel within-subjects contrast between earlydeveloping and later-developing phonemes. Previous work has used descriptive designs or has 
focused on between-subjects contrasts (e.g. a poor vocabulary group versus a strong vocabulary group) to examine long-term knowledge effects on word learning, however it is difficult to control because of many confounds like language experience, exposure to vocabulary, and other cognitive and linguistic abilities. Using a within-subject experimental contrast provides a novel approach to examine the role of long-term phonological knowledge on word learning performance.

\section{Background}

\subsection{Word knowledge in typical development and language impairment}

\subsubsection{Relationship between vocabulary and typical reading development}

This section discusses some evidence demonstrating the impact of vocabulary knowledge on reading in order to underscore the importance of this general area of study and the need to understand the mechanisms involved in vocabulary acquisition. This will ultimately aid in the development of appropriate interventions designed to help remediate impaired word learning ability.

For example, within a sample of typically developing children, Fowlert and Swainson (2004) found a correlation between vocabulary knowledge and reading ability between groups identified as good readers and groups identified as poor readers. Children performed both receptive and expressive naming tasks, and the children identified as poor readers were less accurate in expressive naming tasks than their peers. The authors suggest the struggle to name words orally stems from the imprecise representation of words in the lexicon. It was found that "conceptual or terminological limitations (p. 267)" could not explain naming deficits in children identified as poor readers. A word with a weak phonological representation is harder to retrieve in the lexicon and may be replaced with a broader term. Children identified as having stronger 
reading skills were able to name the picture faster and used more precise terminology than children identified as having weaker reading abilities.

Work by Muter, Hulme, Snowling, \& Stevenson (2004) demonstrates that vocabulary knowledge is a significant predictor for reading comprehension. Muter and colleagues studied the extent to which grammatical abilities, phonological abilities, and vocabulary knowledge predicted reading ability in children. The authors specifically studied two aspects of reading ability, word recognition and reading comprehension. Ninety children were tested three times throughout a two year period. The investigators found that phonological abilities (as measured by phoneme sensitivity and letter knowledge) were predictors of word recognition. Grammatical awareness and vocabulary knowledge were also found to be significant predictors of reading comprehension. According to these findings, as children learn to read, phoneme knowledge and letter recognition are used to facilitate word recognition and vocabulary growth. As reading content increases in complexity, children rely more on vocabulary and grammatical (morphological and syntactic) information to comprehend what is being read. If vocabulary, as a predictor of reading ability, is limited, children may have increasingly more difficultly comprehending written material.

There is also evidence that shows a relationship between the knowledge of word structures, phonological knowledge, and reading. Casalis and Louis-Alexandre (2000) conducted a study that examined the relationship between morphological analysis, phonological awareness, and learning to read by performing a longitudinal study on typical French children from the end of kindergarten to $2^{\text {nd }}$ grade. Casalis and Louis-Alexandre measured these relationships by having the children participate in a drawing-choice task, completion tasks, word segmentation 
and word synthesis tasks, as well as several phonological awareness tasks like rhyme choice, phoneme deletion, and syllable deletion.

Morphological skills such as drawing-choice and synthesis improved significantly from kindergarten to $2^{\text {nd }}$ grade. There was also significant growth in phonemic segmentation from kindergarten to $2^{\text {nd }}$ grade. Their findings showed an increasingly stronger correlation between morphological awareness and phonological awareness at each time the children were tested (kindergarten, $1^{\text {st }}$ and $2^{\text {nd }}$ grade). Overall they found that there was a correlation between children's morphological analysis ability in kindergarten and their reading ability in $2^{\text {nd }}$ grade. The results indicate that children with poor phonological and morphological abilities as early as kindergarten could be at risk for falling behind in reading ability in later elementary school years.

Vocabulary knowledge (and knowledge of word structures) has an important role in the ability to recognize and read words later in life. Thus, if word learning is impaired, children will likely be susceptible to falling behind their peers at an early age, and will have difficulty catching up to their peers as reading becomes more critical for learning in upper grade levels.

\subsubsection{Word knowledge and language impairment}

Specific Language Impairment (SLI) is a developmental language disorder that impairs language form, content, and use. Children with SLI have been found to have decreased vocabulary and lexical knowledge compared to their typical peers, and often these deficits are the first diagnostic indicators of language impairment (Bishop, 1997; Mainela-Arnold, Evans, \& Coady, 2008; Watkins, Kelly, Harbers, \& Hollis, 1995). It is thought that SLI results from deficits in the underlying mechanisms involved in learning language which leads to impairments in areas such as phonological and morphological skills and word knowledge (Ullman \& Pierpont, 2005 Ullman \& Gopnik, 1994). The focus of this section will be on how poor word learning 
skills, as exhibited in children with SLI, impact how words are stored and retrieved from within the lexicon.

Dollaghan (1998) explored how children with and without SLI differed in the amount of acoustic information they need to recognize three types of words. To ensure words were unfamiliar to both groups, Dollaghan used made up words, or nonwords (e.g. /wa $/$ / and /bil/), words that were familiar and phonologically related (e.g. /wat $/$ and /bid/), and words that were familiar and phonologically unrelated (e.g. /klaon/ and /bout/). Using two tasks, a word learning task and a gating task, Dollaghan examined the ability to learn and then retrieve new words. The word learning task involved four nonword target words paired with a novel referent. Each child was told they were going to learn a new word prior to the task. The gating task involved an activity that gave the child increasing phonological increments of a monosyllabic word and the child was asked to guess the whole word based on the pieces revealed one at a time. The words used in the gating task were monosyllabic familiar words and the nonwords the children had learned during the study.

Dollaghan found that children with SLI required more acoustic-phonetic cueing in the gating task to identify newly learned words. It was also found that typically-developing peers were more likely to include the target word's initial consonants when presented with already familiar words, whereas children with SLI were less likely to include the target word's initial consonants for these trials. The children with SLI needed more acoustic-phonetic cueing in the gating task to identify newly learned words. Dollaghan suggested that the difficulties and processing delays seen in children with SLI would be the most damaging during the years the children were acquiring and learning new language. Their deficient language system would 
create a "bottleneck" effect (p. 204) that would hamper their processing and learning of new words to be stored properly within the lexicon.

A similar gating study by Mainela-Arnold et al. (2008) was performed using school age children with SLI and their age-matched peers to investigate whether children with SLI would differ in the amount of acoustic information they needed to identify words with varied word frequency and neighborhood density. Neighborhood density refers to the number of words that are similar to a target word (Roodenrys, Hulme, Lethbridge, Hinton, \& Nimmo, 2002). Because words with high phonological neighborhood density have many 'neighbors' with similar sound patterns, typically more information is required to correctly recognize them during a gating task. Mainela-Arnold and colleagues hypothesized that children with SLI would experience less of a response to neighborhood density than their typical peers in identifying words, and that they would be just as efficient as their peers in identifying high frequency words. If the results supported these predictions, it would indicate that children with SLI have less phonological detail and thus a more holistic representation of words within the lexicon. Using age-appropriate monosyllabic words, the researchers administered a gating technique similar to the Dollaghan study (1998) in which the children were instructed to guess a whole word based on hearing a small part of the word in increments.

The results indicated that children with SLI did not have holistic representations of words within their lexicon as compared to their age-matched peers, as was hypothesized. Children with SLI needed similar amounts of acoustic information to identify gated words as their typical peers. Recognition of words by children who have SLI was not affected by word frequency. Also, children with SLI were just as likely to guess words that shared initial sounds with the target words, contrary to what Dollaghan (1998) found. The main difference found between the 
subject groups in the study was that children with SLI chose words with no apparent phonological relationship to the target words more often than their peers. The investigators reported that the children with SLI vacillated between words and were more vulnerable to selecting the wrong word indicating that there is a difference in lexical representations between children with SLI and their age-matched peers. However the difference is not that children with SLI have more holistic representations in their lexicons. Based on these findings it seems that lexical access of words within the lexicon of children with SLI is more susceptible to competition than typical peers, and they are more likely to select the wrong word when retrieving words from the lexicon.

These studies demonstrate that children with SLI are more likely to use the incorrect word when selecting words from their lexicons resulting in decreased word naming accuracy and more difficulty producing spoken words. Although it is unclear whether these children have poor lexical representations or deficits in the ability to retrieve lexical information (or both), this literature provides evidence linking poor use of lexical representations with language impairment.

\subsection{Long-term memory, short-term memory, and word learning}

The previous section highlighted some of the evidence suggesting that word knowledge plays a critical role in typical development, and that deficits of word knowledge can be linked to language impairment. In order to facilitate vocabulary acquisition and to develop appropriate interventions for those with language deficits, it is important to understand the underlying mechanisms involved in learning new words. The following section focuses on two of the primary systems involved in learning new words: long-term and short-term memory.

Long-term memory and short-term memory are believed to work together to integrate learned words into the mental lexicon. Short-term memory is suggested to be the pathway to 
long-term memory in which new verbal information is rehearsed, processed, and fed into longterm storage (Gupta, 2003). To examine the relationship between long-term memory and shortterm memory, Gupta (2003) conducted a study in which he compared the performance on a word learning task to a nonword repetition task and an immediate serial recall task (digit recall) because these two tasks are thought to measure aspects of short-term memory. Gupta found that the word learning task correlated with the nonword repetition task and digit recall task. It was concluded that, within adults, word-learning requires activity from both short-term and long-term memory and that the relationship between short-term and long-term memory is bi-directional. Gupta refers to a common sequencing mechanism hypothesis. According to this account, direct short-term connections exist between the sequence memory (responsible for coding words in serial order, or like lists) and the lexical and sublexical phonological levels of representation. The lexical level provides linguistic representations of words which activate the sequence memory, and the sublexical level temporarily repeats and maintains the syllabic sequence. Similar evidence has been shown with children during word learning paradigms (Gathercole \& Baddeley, 1989; Gathercole, Willis, Baddeley, \& Emslie, 1994; Gathercole, Service, Hitch, Adams, \& Martin, 1999; Gupta, 2003) . Gupta purports that the similarities in adult word learning and child word learning results suggest that this mechanism is a fundamental component of cognitive design.

Gupta's findings that word-learning, nonword repetition, and immediate serial recall are correlated provide indirect evidence that damage to long-term memory could negatively impact word-learning abilities. For example, if the quality of long-term phonological knowledge (or phonological representations) is degraded, then this weak or degraded phonological information being rehearsed in the short-term memory mechanism is potentially impairing word learning 
abilities. In another example, if there is slow access and retrieval of phonological representations such that it takes longer for the phonological information to move into the short-term memory mechanism, it could result in decreased memory storage capacity, decreased accuracy, and decreased opportunities to rehearse new word items.

The previous examples describe the consequences of impaired long-term knowledge negatively affecting short-term memory, leading to potential deficits in word learning. According to Gupta's supposition that the relationship is bi-directional, if the bi-directional pathway connecting short-term memory and long-term memory becomes impaired, this could also lead to deficits in transferring new information from short-term memory into long-term storage. How short-term memory processes information is key to understanding how this transfer of new information is integrated with the old. Processing new verbal information has great impact upon the quality of phonological knowledge in long-term memory. In fact, short-term memory deficits are commonly seen among individuals with language impairments (Baddeley, 2001; Gathercole \& Baddeley, 1989), suggesting that the short-term memory mechanism is necessary for typical language acquisition.

\subsubsection{Short-term memory}

Short-term memory, as proposed by Baddeley and Hitch (1974), consists of three components: the phonological loop, the visuospatial sketchpad, and the central executive. The area of interest for this project is the phonological loop in which verbal information is processed. The phonological loop consists of a phonological store and an articulatory rehearsal mechanism. Using the two previously discussed components, the phonological loop temporarily stores and rehearses brief amounts of phonological information so that it is fresh and readily available for immediate use (Baddeley, 2001; Baddeley \& Hitch, 1974). 
There have been many studies aimed toward identifying how verbal information is processed within short-term memory. A leading theory is that verbal information is processed in serial order like a list (Gupta, 2005; Gathercole, 2006; Baddeley, 2001). For example, when participants are asked to recall a list of items, improved recall is typically seen with items at the beginning of the list (primacy effect) and with items at the end of the list (recency effect) compared to items in the middle of the list. Gupta, Lipinski, Abbs, and Lin's (2005) data supporting serial processing of verbal information in short-term memory in a series of five experiments in which adults were asked to complete nonword repetition tasks. Nonwords of 4- to 7-syllables in length were presented one at a time, and participants were asked to repeat aloud the nonword immediately after hearing it. Results of all five experiments showed primacy and recency effects, supporting the idea that words are processed like lists within the short-term memory mechanism as Gupta proposed in the common sequencing mechanism hypothesis.

\subsubsection{Long-term knowledge}

The integration of new information to the lexicon plays an important role in the strength of the mental representation of the word. How words are learned affects how words are selected from the lexicon. Dell (1986) proposes a model of word activation that involves multiple processes when deciding which word to choose for speech production, known as the spreadingactivation theory. Based on language context, during speech production planning, an individual selects a word from long-term memory and the word is fully constructed in short-term memory, or within the unknown mechanism that connects short-term memory to long-term memory. Once the word has been chosen, the construction of morphemes is gathered and organized for articulation in a process Dell refers to as phonological encoding. According to this account, phonological and phonetic feature information (e.g. place of articulation, manner of articulation, voicing) are also available during phonological encoding. As an interactive model of speech 
processing, phonological neighbors of the word are also activated to facilitate processing of the word. For example, when planning for the production of 'buzz,' phonologically similar words like 'fuzz,' 'was,' 'bus,' 'bud,' and so on are also activated. Through ongoing interactions between input information, context, and activated representations, the 'unwanted' phonological representations, or competitors, are suppressed. If a word consists of weak or degraded phonological representations, then it will be more difficult to 'rule out' competitors, which can result in production errors.

Levelt's (2001) account of spoken word production also demonstrates the effect of the quality of phonological representations in speech production. In planning for production, Levelt's model involves several steps in the selection of a word within the lexicon. The first step is perspective taking, which refers to the selection of a word to serve a particular communication goal. Once the word has been chosen, this triggers the "activated" word within the lexicon, or lemma. For example, when asked to name a picture of an apple, the lemma 'apple' can activate other words such as 'food' or 'fruit'. The target lemma, which in the previous example would have been 'apple', is selected from competition of the other activated words. Levelt suggests a competition takes place during lemma selection so the strongest and most specific lemma is chosen for the word. Once the lemma has been selected, the encoding system is triggered, which allows phonemes for the selected lemma to be chosen over other activated lemmas' phonemes. The phonemes are selected in the order they are needed. Within the encoding system, a process known as syllabification occurs, allowing content specific phonemes to be added, such as plurals or other grammatical markers. This system constitutes a competition-based word and phoneme selection process in which a word with the strongest phonological representation is selected. 
In summary, Levelt's model first focuses on a single lexical item appropriate for the speaker's intentional state, and second, generates an articulatory score for the item in its appropriate context. Levelt proposes that these two systems develop separately in children causing weak cerebral links for language production leading to errors in function and structure seen during the course of development. According to Levelt's model, a word that does not have a strong phonological representation will not always be selected from the lexicon. Levelt notes that the selection process and the articulatory process are dependent upon one another. If a selected lemma is degraded the articulatory process cannot properly form the word to produce, which can lead to eventual speech production errors.

Although these two models account for speech production differently, both explain that impaired phonological representation in long-term memory can result in speech and language errors. It is a logical extension of these speech production models to suggest that in other linguistic tasks like nonword repetition and word learning, degraded phonological representations could also be subject to slower activation, more competition, and decreased accuracy when retrieved for online rehearsal and manipulation in short-term memory. Phonological representations that are poorer in quality could be more difficult to maintain in short-term memory and more prone to decay (Baddeley et al, 1998; Gathercole \& Baddeley, 1989, 1990a), thus impeding the mechanism of transferring a novel lexical item from short-term to long-term memory.

\subsubsection{Long-term memory and word learning}

The previous section discussed how leading models of speech production demonstrate that the varied quality of phonological representations can result in production deficits. Here is evidence to show that the quality of long-term phonological representations impacts word learning and retrieval abilities for typically developing children and for children with language 
impairments. Metsala, Stavrinos, and Walley (2009) studied changes in spoken word recognition of typically developing children from two different age groups over the course of a year. Specifically they sought to determine if older children would need less acoustic-phonetic input on a gating task and become more accurate on a nonword repetition task than younger children. The team also examined if spoken word recognition and phonological awareness were related. The investigators used a group of younger children $\left(1^{\text {st }}\right.$ and $2^{\text {nd }}$ graders $)$ and a group of older children $\left(3^{\text {rd }}\right.$ and $4^{\text {th }}$ graders $)$ and administered a gating task, a word repetition task, initial phoneme isolation, initial phoneme deletion, and nonword repetition to discern how phonetic input impacts word recognition. Each participant completed the study twice; the second task was completed one year after the first experimental task.

Children were able to perform faster on the gating task as they got older, despite their growing lexicon. Older listeners were better at identifying earlier acquired words on the gating task. A competition effect was also present during the gating tasks for both the younger and older groups, and was seen much more strongly in earlier acquired words. The investigators suggested that these results indicate competition emerges with lexical development (i.e., more words create more competitors). Children who had low spoken word recognition scores had poor phonological awareness and reading scores. Children who struggled with spoken word recognition of lowfrequency words also had poor phonological awareness abilities.

Metsala and colleagues concluded that, "there may be a developmental sequence such that segmental processing is tied to lexical characteristics, but then becomes independent in normal development. This 'freer state' of phonological processing may be hampered in some children, who later have trouble learning the alphabetic code (p. 116)." In summary, as children mature they have more specified knowledge of the segments of words and may utilize these 
segments independently when learning new words. Children with poor phonological awareness or poor literacy skills have difficulty with this maturation process so that they may not be able to utilize the segments of words as readily and, therefore, have to rely more on their whole-word knowledge.

Evidence suggests that long-term phonological knowledge also plays a role in the performance of children with language impairments. Nonword repetition tasks, serial recall tasks, and word-learning tasks have been found to be strongly correlated in children, and good predictors of word learning ability (Gupta, 2003; Gupta et al, 2005). Of these tasks, nonword repetition seems to have received the greatest attention in exploring the varied possible causes of language impairment. As described previously, nonword repetition involves the immediate repetition following presentation of a nonword. This has resulted in the over emphasis of the task as a measure of phonological short-term memory, and therefore, an emphasis on short-term memory deficits as a potential factor in explaining language impairments (e.g. Coady \& Evans, 2008). However, it is well known that nonword repetition is a task that relies on multiple processes like auditory perception, speech production, and long-term knowledge (e.g. Coady \& Evans, 2008; Graf-Estes, Evans, \& Else-Quest, 2007; Moore, 2012). Deficits in any of these processes could lead to decreased performance and be indicative of language impairment.

For example, Archibald and Gathercole (2007) examined why nonword repetition tasks are a discriminator of language learning ability. The study used two groups of children, one group of children with SLI and a group of typically developing age-matched peers. There were two tasks in this study, a nonword repetition task and a serial recall task. The scores of the SLI group were significantly lower than the age-matched group on both tasks, but the magnitude of the effect was greater in the nonword repetition than the serial recall task, so that the poor 
phonological memory storage capacity could not entirely explain the poor performance of the SLI group on the nonword repetition task. Archibald and Gathercole concluded that there is an underlying deficit that affects another mechanism responsible for processing multisyllabic words. This underlying deficit may prevent the online use of phonological representations without decay or degradation, thus preventing a speedy and accurate recall of longer novel words in children with SLI. It is reasonable to think that this deficit may then prevent the learning of more complex multisyllabic vocabulary words for children with SLI.

As the focus of this project is on the influences of long-term knowledge on word learning, and because word learning is related to phonological memory (as measured by nonword repetition; Gupta 2003), the following section will review some evidence that demonstrates the role of long-term lexical and phonological knowledge in nonword repetition, namely from lexicality and phonological development effects in performance.

\subsection{Lexicality effects in nonword repetition}

Long-term memory influences how new words are processed by comparing novel words to words already stored within the lexicon. This effect is known as lexicality: the "lexicality effect appears to arise from the use of activated lexical representations to reconstruct incomplete representations held in the phonological loop at the point of retrieval (p. 519-520)" (Gathercole, 2006; Gathercole, Frankish, Pickering, \& Peaker, 1999; Gathercole, Pickering, Hall, \& Peaker, 2001; Hulme, Roodenrys, Schweickert, Brown, Martin, \& Stuart, 1997; Schweikert, 1993; Thorn, Gathercole, \& Frankish, 2005). Nonwords with high lexicality (i.e. very wordlike) are typically processed more accurately than non-wordlike stimuli. Similarly, when errors are made in tasks like nonword repetition, the errors typically result in the nonword or constituent syllables of the nonword becoming more wordlike. This effect is believed to be caused by activation of long-term lexical knowledge (Gathercole, 2006); long-term memory is supplying stored 
information to help process current information. It is believed that when a nonword resembles a real word a door is opened to long-term storage and the representation of the nonword is replaced by a real word (Gathercole, 2006). This effect is not only seen in nonwords, long-term memory influences have also been studied in real words as well and have been considered a way to help learn new vocabulary by supplying old knowledge.

A lexicality effect has been observed in typically developing children at varying ages. For example, Munson, Swenson and Manthai (2005) conducted a study examining the repetition of real words and nonwords in two different groups of typically developing children (mean age of $7 ; 2$ and $4 ; 3$ ). Using real words and nonwords, they found different patterns of recall between the two groups. Children with larger vocabularies, which in this study are the older children, had greater lexical competition. In other words, it took them longer to repeat words from larger phonological neighborhoods because their vocabulary already contained these similar words. Another of the study's findings was phonological facilitation during the nonword repetition task, resulting in faster repetition times in the older group of children for nonword items with increased phonotactic probability, which is "the measure of the frequencies of occurrence of the sequences of sounds making up a word or nonword (p. 109; Munson et al, 2005; Frisch, Large, \& Pisoni, 2000; Vitevitch \& Luce, 1998, 1999)". These results led Munson and colleagues to conclude that "lexical competition and phonological facilitation emerge in development (p. 109)".

Lexicality effects resulting from lexical competition and phonotactic probability are a result of increased word knowledge. Participants will "recognize" a nonword more quickly because of the nonword's resemblance to a real word. When a word is heard for the first time, it essentially resembles a nonword until the word and its meaning can be learned through continued 
experience and repeated exposures. Initially in the word learning process then, we might expect that the effects of long-term word knowledge like lexical competition and phonotactic probability would have similar effects as those seen in the repetition tasks by Munson and colleagues. These results provide strong evidence to suggest that previously stored lexical information from long-term memory can be used to facilitate short-term memory when learning a new word (Gathercole, 2006).

\subsection{Rationale of current project}

Based on studies correlating long-term memory, short-term memory, and word learning there exists strong evidence to suggest that the quality of phonological representations can affect the acquisition of new words. This evidence has also been demonstrated with lexicality effects in nonword repetition studies contrasting groups with normal versus impaired language, strong vocabulary knowledge versus weak vocabulary knowledge, and normal reading ability versus impaired reading ability. However, a limitation to these types of descriptive studies contrasting two distinct groups is that there are many external factors (e.g. experience, education, environment, etc.) that could affect interpretation of poor word learning outcomes. Another approach is to use a within-subject experimental design to control the potential confounds that are inherent in between-subjects design. To account for these potential confounds, a contrast of early-developing and late-developing phonemes was employed, as described in Moore (2012). Moore argued that because early-developing phonemes are acquired before later-developing phonemes, they become more central within neural networks and, therefore, have an increased number of neural connections and more utility than later developing phonemes. Because this structure is reinforced over time, it creates a potential model of varied quality of long-term phonological representations within normal adults. 
Studies have shown that during nonword repetition, nonwords containing laterdeveloping phonemes have decreased accuracy compared to nonwords containing earlydeveloping phonemes (Moore, 2012; Moore, Tompkins, \& Dollaghan, 2010). This early-late phoneme (ELP) effect was also seen during a single-word reading task and auditory and visual lexical decision tasks with and without concurrent articulation, demonstrating that the effect crosses perceptual and articulatory modalities (Moore, 2012). The evidence from these studies indicates that the ELP effect persists when other factors such as auditory perceptual demands, articulatory demands, and phonological memory are minimized or eliminated; suggesting that the ELP contrast could be a result of varied quality in phonological processing for early versus late phonemes.

The purpose of the current study is to examine the varied quality of long-term phonological knowledge within a single individual (as operationalized with the ELP contrast) and its influence on word learning. Based on previous work, it is predicted that participants will experience greater difficulty learning novel words containing potentially weaker phonological representations (late-developing phonemes) than words containing potentially stronger representations (early-developing phonemes). Using the ELP contrast, insight may be gleaned as to how the strength of long-term phonological knowledge affects word learning abilities for normal individuals, which could be extended in future work to understand the theoretical constructs of language learning disabilities.

\section{Methods}

The current research focused on phonological knowledge and word learning ability. The study consisted of a nonword repetition task and a word learning task containing a contrast of early-developing and late-developing phonemes. The nonword repetition task was a replication 
of previous work (Moore, 2012; Moore et al., 2010) to demonstrate the documented early- and late-phoneme differences in this study with different equipment and subject sample. The word learning task was used to examine the effects of long-term phonological knowledge in acquiring new words. In addition to these two tasks, subjects completed subtests of the Woodcock Reading Mastery Test - III (WRMT-III; Woodcock, 2011) and the Comprehensive Test of Phonological Processing - 2 (CTOPP-2; Wagner, Torgesen, Rashotte, \& Pearson, 2013).

\subsection{Technical Specifications}

\subsubsection{Stimulus Development and Presentation}

The nonword repetition task in this study used the digital audio files of the nonword stimuli from Moore (2012). All stimuli were digitally recorded in a quiet room by a female speaker of Standard American English. An Audio-Technica ATR120 low impedance, dynamic microphone was used at a consistent mouth-to-microphone distance of one inch. Audio files were recorded onto a computer using Adobe Audition 1.5 (44,100 Hz sampling rate and 16-bit resolution). The nonwords were presented auditorily through Sony Dynamic Stereo MDR-V6 Headphones. The presentation volume was set to a comfortable level as determined by pilot subjects and was held constant across all participants and all tasks.

The word learning task in this study used 6 nonwords from Moore's (2012) nonword repetition task. These 6 nonwords served as the target words during the word learning task. The 72 nonword foils used during word learning were digitally recorded in a quiet room by the same trained female speaker who recorded the nonword stimuli from Moore's (2012) task. Audio files were recorded with a SHURE SM48-LC unidirectional, dynamic vocal microphone using a NADY MPF-6 Pop Filter and Adobe Audition CS6. All 78 sound files used in the word learning task were normalized using Adobe Audition to be the same length (1.4 seconds) and amplitude (22.78 decibels). 
All visual stimuli were displayed in white against a black background. The instructions of the nonword repetition task were presented in Arial 30-size font. The instructions of the word learning tasks used Courier New 18-size font. All visual images in the word learning tasks were cropped, framed, and adjusted for size using Adobe Photoshop CS6.

\subsubsection{Participant Responses}

In order to complete offline scoring and data entry, responses for non-computer based tasks (brief history and family history questionnaires and the WRMT-III) were recorded using a SONY Digital Voice Recorder ICD-PX312 and were uploaded to a computer via USB PC link. For the computer-based tasks (CTOPP-2 subtests, nonword repetition, and word learning), participant responses were recorded digitally using an external Logitech microphone and Adobe Audition CS6. The microphone was placed on the desk directly in front of the participant and did not interfere with their access to the screen or keyboard.

\subsection{Participants}

Participants were recruited using flyers posted around academic buildings on both the Downtown and Evansdale campuses of West Virginia University. The study information was also posted on the Language and Literacy Lab website on the Communications Sciences and Disorders webpage. The following criteria were used to recruit for this study: adults from West Virginia University ranging in age from 18-26, native English speakers, no history of hearing disorder, no history of vision impairment (that was not correctable by glasses/contacts), no history of speech, language, or reading disorder, no history of neurological disorder, and had not learned or spoken a second language at home.

A total of 30 students from West Virginia University were enrolled in the study (6 males, 24 females; 28 right-handed, 2 left-handed). Subject ages ranged from 18-27 years old $(M=$ $21.63, \mathrm{SD}=2.83)$; their years of education ranged from $1-6$ years in college $(M=3.7, \mathrm{SD}=$ 
2.05). The participants consented to testing prior to the initiation of the experiment as approved by the West Virginia University Internal Review Board. All participants, upon completion of the study, were compensated with a \$20 Amazon.com gift card.

During the testing session, each participant reported having spoken only English in the home, and no vision problems that could not be corrected with glasses or contacts. Each participant passed a hearing threshold screening with hearing thresholds $<25 \mathrm{~dB}$. Eight participants reported having a family history of communication deficits. In spite of providing no mention of a history of speech, language, reading, or cognitive deficits during recruitment, seven participants reported one of the following on the questionnaires during the testing session: currently has Attention Deficit Hyperactivity Disorder $(n=1)$, has a history of a dysfluency disorder which was treated with speech therapy $(n=1)$, had a mild articulation disorder in elementary school which was treated in speech therapy $(n=2)$, received reading intervention in elementary school $(n=2)$, and has a history of concussions $(n=1)$. However, upon examining their individual scores for the experimental tasks, their scores appeared to follow the pattern of performance of the participants, so their data were included in the analyses.

\subsection{Testing Procedure}

All procedures were administered individually in a quiet testing room. After consenting to participate, each participant completed a brief history questionnaire, a hearing threshold screening, and a family communication history questionnaire regarding the subject and their birth families' speech, language, cognitive, hearing, and reading backgrounds. Hearing thresholds were screened using the Earscan 3 to determine if hearing was within normal limits, at a decibel level of 25 or less, for the following frequencies: $500 \mathrm{~Hz}, 1 \mathrm{KHz}, 2 \mathrm{KHz}$, and $4 \mathrm{KHz}$.

After these initial tasks were completed, the experimental nonword repetition task was administered, followed by test phases 1 and 2 of the word learning task. Details about the 
stimuli, administration, and scoring for these tasks are provided in the following sections. After the participant completed test phase 2 of the word learning task, two subtests from the CTOPP-2 were administered through audio files on the computer. Each participant was given the option to take a 5 minute break before completing the four subtests of the WRMT-III and test phase 3 of the word learning task. The entire study session lasted approximately 1.5 hours, with some participants taking as long as 1.5 hours to complete all of the tasks, and other participants completing all of the tasks in approximately 1 hour.

\subsection{Baseline Measurements}

All participants were administered the Memory for Digits and Nonword Repetition subtests of the CTOPP-2. They also were administered the following four subtests of the WRMT-III: Word Identification (a measure of single word reading), Word Attack (a measure of the ability to apply phonological analysis skills to unfamiliar words using nonwords), Word Comprehension (a measure of reading vocabulary using synonyms, antonyms, and analogies), and Passage Comprehension (a measure of comprehension and vocabulary skills used to identify a missing word in a passage). These tests were given to obtain a baseline of short-term memory, phonological and word knowledge, and basic reading ability of the participants. These tests were placed after the nonword repetition task and the word learning test phases 1 and 2 for two reasons: 1) so that the standardized subtests would not influence performance on the experimental tasks (particularly the CTOPP-2 Nonword Repetition and WRMT-III Word Attack), and 2) so that there would be 25-30 minutes between Test Phase 2 and Test Phase 3 of the word learning task in order to measure learning over time. 


\subsection{Nonword Repetition}

\subsubsection{Stimuli}

The consonants used in the nonword repetition task were based on the Early-8, Middle-8, and Late-8 order of acquisition (Shriberg, 1993; Shriberg \& Kwiatkowski, 1994). Seven phonemes were selected from the Early- 8 and Middle- 8 consonants to be included as the earlydeveloping phonemes (E7) in this study: /m, n, d, p, t, f, v/ and seven phonemes were selected from the Late-8 group to be used as late-developing phonemes (L7): /s, z, 1, r, $\int, \theta$, ð/. The vowels and diphthongs that were used in the nonwords were /a, æ, e, o, u, av, aI, oI/. These vowels are all tense vowels with the exception of /æ/. They were chosen to be used in the stimuli because they are less susceptible to schwa reduction and are considered to be easily perceptible (Dollaghan \& Campbell, 1998; Moore, 2012).

There were 32 nonwords, 16 nonwords for each phoneme type (E7 and L7), ranging in length from one to four syllables. The final syllable for all nonwords had a CVC structure; all other syllables had a CV structure. The nonwords were carefully designed on a number of parameters to control for length, number of occurrences of each phoneme, phonotactic probability, and lexicality (see Moore, 2012 for details).

\subsubsection{Task administration}

This task was presented on a computer using E-Prime, a software program for administering psychological experiments (Schneider, Eschman, \& Zuccolotto, 2002). The participant read the following instructions presented on the screen to start the nonword repetition task: 'You are going to listen to a series of made-up words presented one at a time. When the fixation point turns green, repeat the made up word out loud. Say the words exactly the way that you hear them. The first few will be practice. Press any key to begin with the practice items.' Following the practice items, the task began with one-syllable nonwords, and then continued 
with 2-syllable nonwords, and so on increasing syllable length. E7 and L7 nonwords were presented in random order at each syllable length.

For each trial, a red fixation cross displayed on the screen 0.5 seconds prior to the onset of a nonword and remained on the screen throughout the auditory presentation of the nonword. After the stimulus presentation, the fixation turned green to prompt the participant to repeat the nonword. The green fixation cross remained on the screen for 2.5 seconds, followed by 0.5 seconds of the red fixation, then the next nonword item, and so on. There were a total of 3 seconds between each item (Moore, 2012).

\subsubsection{Nonword Repetition scoring}

Scoring of the nonword repetition task was completed according to the procedure described by Dollaghan and Campbell (1998) and was consistent with Moore's (2012) study. Each phoneme was scored 1 for correct or 0 for incorrect to obtain a percentage of phonemes correct (PPC). Each syllable length PPC was calculated (1PPC, 2PPC, 3PPC, 4PPC) as well as an overall percentage (TOTPPC). All omissions and substitutions were counted as incorrect. Additions were noted but were not included in the PPC. In the cases in which the participant did not repeat the nonword in its entirety due to laughter or inability to repeat the word within the timeframe, the total number of phonemes repeated correctly was divided by the total number of scoreable phoneme targets. In one case the subject did not repeat the target nonword at all; in this instance the nonword was not scored.

\subsection{Word Learning}

The word learning task in this study was based on Gupta's task from his 2003 experiment correlating word learning, nonword repetition, and immediate serial recall. Gupta used word learning pairs that eliminated contextual knowledge and relied on visual and auditory stimuli only. He used each nonword (presented auditorily) as a label for a novel image (presented 
visually). However, instead of Gupta's nonwords for the target words, six stimuli from the 4syllable E7 and L7 nonwords in the nonword repetition task were selected for this study in order to compare learning differences between items with early- versus later-developing phonemes. To control for exposure to the nonwords prior to the word learning task, each participant first completed the nonword repetition task and then completed the word learning paradigm.

\subsubsection{Stimuli}

As mentioned previously, the three E7 and three L7 4-syllable nonwords from the nonword repetition task were used as target words for the word learning task. The three E7 target stimuli chosen were /maudornapæv, noffaumævat, tedæfumoIn/. The L7 target stimuli chosen

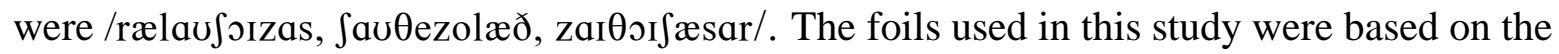
nonword foils used in the Gupta study (2003). However, the foils in the current study were slightly modified to 1) balance the E7 and L7 phoneme count within the foil list, and 2) to include more vowel diphthongs, tense vowels, and E7 and L7 phonemes in order for the foils to sound phonetically similar to the E7 and L7 target words. A paired samples $t$-test was computed to verify that there were no significant differences between the number of E7 phonemes and L7 phonemes that were used within each foil $\left(M_{E 7}=2.61(.808) ; M_{L 7}=2.45(.724) ; p=0.123\right)$. All foils were 4-syllable nonwords.

\subsubsection{Task Design and Administration}

At the start of the task, the participant read the following instructions: 'Hello! You will hear a set of unfamiliar words. When the fixation cross turns green repeat the word aloud exactly as you heard it. Within each set of unfamiliar words, you will be learning the names of TWO different imaginary aliens. When you see an array of aliens, you will hear the name of the alien that is framed in yellow. After you hear the alien's name you should repeat its name aloud 
exactly as you heard it. Try to learn the names of the aliens. Press the space bar to begin.' Then the task began with the exposure phase of the first of the three blocks, described below.

There were three target blocks (one E7 and one L7 target per block) that contained 8 rounds of exposure and test trials. Each round consisted of five exposure trials followed by two test trials. Block order was randomized so that stimuli presentation was balanced across subjects.

The five exposure trials consisted of two target trials intermingled with three foil trials. During the exposure-target trials, the participant was presented with a visual array of alien images. The target image was highlighted by a framed yellow box to cue the participant to learn that alien's name. Simultaneously a nonword representing the name of that alien was presented auditorily. A green fixation cross then appeared above the alien array to cue the participant to repeat the target name aloud. These exposure-target trials were 5.4 seconds in duration: the alien array appeared and remained on the screen (1 s), while the array was on the screen the alien's name was presented auditorily (1.4 s), a green fixation appeared cueing the participant's response $(3 \mathrm{~s})$. The array of aliens was the same for both the exposure and test trials within each target block.

There were three exposure-foil trials with an auditory presentation of a foil nonword, which the participant repeated aloud, but was not asked to learn. The foil nonword did not have an image (other than a fixation cross) presented with it. The foils were selected in random order for each participant and no foil was presented more than once. The red fixation appeared $1 \mathrm{~s}$ before the presentation of the foil to cue the participant to attend to the upcoming stimuli, and it remained on the screen for the duration of the foil presentation $(1.4 \mathrm{~s})$. The fixation cross turned green and remained on the screen for 3 seconds to cue the participant to repeat the foil nonword. 
After the five exposure trials, participants completed two test trials. To begin the test trials, the participant was given the instructions: 'In this phase you will see an array of aliens. You learned two of these aliens' names in the previous phase. When you see one of the aliens highlighted by a yellow frame, recall its name as quickly and accurately as possible. Once you have recalled its name press the space bar. Press the space bar to begin.' In a test trial, the participant was shown the same alien array presented during the exposure-target trials. One of the two alien images that was shown during the exposure-target trials was highlighted by a yellow frame. The participant recalled the name of the alien, and then pressed the space bar to move on to the other alien image shown during the exposure-target trials. The presentation order of the two aliens in the test trials was randomized for each of the eight rounds within a block, so the participant could not predict which alien would be presented first or second in the test trials.

After completing the two test trials, the participant began the next round of five exposure trials, followed by two test trials, and so on. When all eight exposure-test rounds were completed, participants were instructed that they were going to learn two new alien names, and they continued with the proceeding block. Once all three blocks were completed, participants completed test phase 2 in which they were presented with a visual array showing all six aliens whose names they had been asked to learn. Each alien was highlighted one after another and the participant was asked to recall each alien's name. The order of the aliens remained the same for each subject.

This study also included a test phase 3 at the end of the session after the completion of the CTOPP-2 and WRMT-III subtests. This phase was identical to the test phase 2 of the word learning task in which all of the stimuli were presented in a visual array and the participant was asked to recall the name of each target one at a time. The entire procedure described consists of a 
total of 60 test trials across test phases 1,2, and 3, so that each of the 6 target pairs (i.e. nonwordalien pairs) was tested 10 times throughout the experiment (Gupta, 2003; see table 1).

Table 1. (adapted from Gupta, 2003)

Structure of word-learning task

Stimulus

Participant response

Exposure trials

1. Nonword foil

2. Nonword target $1+$ visual array with Target Object 1

Repeat nonword

3. Nonword foil

4. Nonword target $2+$ visual array with Target Object 2

Repeat nonword

Repeat nonword

5. Nonword foil

Repeat nonword

Repeat nonword

Test trials

6. Target pair 1 test

Name Target Object 1 or 2

7. Target pair 2 test

Name Target Object 1 or 2

8. [Repeat Steps 1-7 seven times]

9. [Repeat Steps 1-8 with Target Pairs 3, 4]

10. [Repeat Steps 1-8 with Target Pairs 5, 6]

11. [Test Phase 2: Test Target Pairs 1 - 6]

12. [Test Phase 3: Test Target Pairs 1- 6 after 20-30 min]

Name Target Objects $1-6$

Name Target Objects 1- 6

\subsubsection{Word Learning scoring}

Each test trial was scored for the six target nonwords for a total of 10 recall attempts for

each nonword target: 8 attempts during test phase 1 , one additional attempt during test phase 2 ,

and a final attempt during test phase 3. Accuracy was calculated in the same manner as the

nonword repetition task in which each recall of the nonword was scored based on the PPC. This

method of scoring differs from Gupta's (2003) task because the current study examined the recall

of each phoneme within a nonword whereas Gupta examined whole-word accuracy. Using PPC

made it possible to obtain a more precise contrast of E7 and L7 nonwords in the word learning task.

All omissions and substitutions were given a score of 0 . Additions and distortions were not subtracted from the total, but were identified and scored separately. Unlike the nonword repetition task, if a participant only recalled part of a word, the missing phonemes were given a 
score of 0 . If a participant did not recall a nonword at all they were given a score of 0 on this attempt. If participants recalled the wrong nonword, such as a foil or a different alien name, participants were given a score of 0 on this attempt as well. This slightly different scoring approach was used because there was an unlimited amount of time to recall a nonword during the test trials, unlike the nonword repetition task.

\subsection{Scoring Reliability}

Interrater and intrarater reliability measures were obtained for the experimental tasks in the study as described in Moore (2012) and Dollaghan \& Campbell (1998). Two undergraduate students in Speech Pathology and Audiology, who had previously taken a phonetics course, used participants' digital audio files in order to obtain interrater reliability ratings. One undergraduate independently scored the nonword repetition task, and the other scored the word learning task. A subset of six participants ( $20 \%$ of the sample) was randomly selected for the nonword repetition task. For the E7 items, phoneme-by-phoneme percentages of agreement for judgment of correctness averaged to $98.30 \%$. Phoneme-by-phoneme percentages of agreement for judgment of correctness for the L7 items averaged to $93.40 \%$.

A subset of three participants ( $20 \%$ of the sample) was randomly selected for the word learning task. For E7 items in the word learning task, phoneme-by-phoneme percentages of agreement for judgment of correctness averaged to 96\%, and 95\% for L7 items.

To measure intrarater reliability for the nonword repetition and word learning tasks, the primary scorer (the author) randomly selected two different subsets of participants' digital audio files to re-score (six participants' files were selected for nonword repetition, six participants' files were selected for word learning). The second round of scoring was completed approximately 2-3 weeks after the initial scoring and the author was blinded to the participants' original scores. For the E7 items in the nonword repetition task, phoneme-by-phoneme 
percentages of agreement for judgment of correctness ranged from $98 \%$ to $100 \%$, with an average of $98 \%$. Percentages for the $\mathrm{L} 7$ items ranged from $93 \%$ to $98 \%$, with an average of $96 \%$. For the E7 items in the word learning task, phoneme-by-phoneme percentages of agreement for the judgment of correctness ranged from $95 \%$ to $100 \%$ with an average of $98 \%$. For the L7 items, percentages ranged from $93 \%$ to $99 \%$ with an average of $97 \%$.

\section{Results}

\subsection{Baseline Measurements}

Baseline measurements were obtained using two subtests of the CTOPP-2, the Memory for Digits and the Nonword Repetition Task, as well four subtests of the WRMT-III, Word Identification, Word Attack, Word Comprehension, and Passage Comprehension. These tests examined subjects' phonological and reading abilities as well as lexical knowledge. The average scaled score across all participants was within the normal range (i.e. within $1 S D$ ) of the average scaled score of each subtest (see table 2).

Table 2. Mean $(M)$ and standard deviation $(S D)$ for subtests from the CTOPP-2 and WRMT-III.

\begin{tabular}{ccc}
\hline Test & Subtest & Scaled Score $M(S D)$ \\
\hline CTOPP-2 & Memory for Digits & $12.03(2.37)$ \\
& Nonword Repetition & $8.00(2.44)$
\end{tabular}

WRMT-III

$\begin{array}{cc}\text { Word Identification } & 96.63(9.18) \\ \text { Word Attack } & 96.17(14.66) \\ \text { Word Comprehension } & 101.87(9.80) \\ \begin{array}{c}\text { Passage } \\ \text { Comprehension }\end{array} & 105.77(7.61)\end{array}$

Note. The mean scaled score for all CTOPP-2 subtests is 10 with a $S D$ of 3 . The mean scaled score for all WRMT-III subtests is 100 with a $S D$ of 15 . 


\subsection{Nonword repetition}

The nonword repetition task was conducted to replicate the findings of Moore's 2012 study, i.e. to determine if there are performance differences in nonword repetition for items containing early-developing versus later-developing phonemes in a different group of participants. To analyze the PPC, a 2 x 4 repeated measures ANOVA was computed with phoneme type (E7, L7) and syllable length (1-syllable through 4-syllable) as within-subjects factors. There was a significant main effect of phoneme type, in which performance was significantly lower for L7 stimuli compared to E7 stimuli $\left(F(1,29)=142.10, p<0.001\right.$, partial $\eta^{2}$ $=.83)$. There was also a significant main effect of syllable length $(F(2.41,69.94)=25.10, p<$ 0.001, partial $\eta^{2}=.46$, using Huynh-Feldt estimates to correct for violation of the sphericity assumption). There was not a significant phoneme type $\mathrm{x}$ syllable length interaction $(F(3,87)=$ 2.20, $p=0.094$, partial $\left.\eta^{2}=.71\right)$.

To further analyze the E7-L7 pattern at different syllable lengths, post-hoc pairwise comparisons using one-tailed paired sample $t$-tests (corrected for multiple comparisons using a Bonferroni adjustment) were computed (see Table 3). Participants scored significantly lower on L7 nonwords at all syllable lengths and overall compared to E7 nonwords $(t \geq 6.13, p \leq .0001)$. 
Table 3. Results from one-tailed paired-sample $t$-tests for the nonword repetition task at each syllable length (adapted from Moore, 2012).

\begin{tabular}{|c|c|c|c|}
\hline Score & $\begin{array}{c}\mathrm{E} 7 \\
M(S D)\end{array}$ & $\begin{array}{c}\mathrm{L} 7 \\
M(S D)\end{array}$ & Test Statistics \\
\hline 1PPC & $97.50(3.88)$ & $90.83(5.93)$ & $\begin{array}{c}t(29)=6.13 \\
p<0.001^{*} \\
d=1.35\end{array}$ \\
\hline 2PPC & $98.50(2.33)$ & $91.00(6.99)$ & $\begin{array}{c}t(29)=6.42 \\
p<0.001^{*} \\
d=1.46\end{array}$ \\
\hline 3PPC & $95.67(2.73)$ & $87.26(10.80)$ & $\begin{array}{c}t(29)=4.15 \\
p<0.001^{*} \\
d=1.09\end{array}$ \\
\hline 4PPC & $89.53(8.11)$ & 77.92 (11.09) & $\begin{array}{c}t(29)=8.75 \\
p<0.001^{*} \\
d=1.22\end{array}$ \\
\hline ТОТРРС & $95.30(2.65)$ & $86.77(5.20)$ & $\begin{array}{c}t(29)=11.94 \\
p<0.001^{*} \\
d=2.10\end{array}$ \\
\hline
\end{tabular}

\subsection{Word learning}

All 30 participants completed the word learning task. Due to equipment error, 1

participant's responses were not recorded for test phase 3 . This subject was excluded from the repeatd measures ANOVA described below, but was included in post-hoc comparisons for test phase 1 and 2.

The word learning task was performed to examine the role of long-term phonological knowledge on learning new words by comparing word learning performance of nonwords containing only E7 consonants to nonwords containing only L7 consonants. To analyze recall differences of E7 target words versus L7 target words, a 2 x 3 repeated measures ANOVA was performed with phoneme type (E7, L7) and test phase $(1,2,3)$ as within-subject factors. Results 
showed no main effect of phoneme type $\left(F(1,28)=2.52, p=0.124\right.$, partial $\left.\eta^{2}=.083\right)$, indicating that, collapsed across test phases, there was no significant difference in recall accuracy of nonwords containing E7 or L7 phonemes. A main effect for test phase was found $(F(2,56)=$ 152.92, $p<.0001$, partial $\left.\eta^{2}=.845\right)$ signifying that overall accuracies are different between the three test phases. Importantly, there was also a significant interaction between test phase and phoneme type $\left(F(2,56)=4.24, p=.019\right.$, partial $\left.\eta^{2}=.132\right)$, indicating that recall differences between E7 and L7 phonemes varied significantly within the different test phases.

To further examine the interaction effects, one-tailed paired sample t-tests (corrected for multiple comparisons using a Bonferroni adjustment) were computed in a post-hoc analysis to compare early- versus late-phoneme differences within each test phase (see Table 4). Significant differences were found in test phase $1(p<.0025)$, such that the average recall accuracy of words containing only L7 phonemes was significantly lower than the accuracy of words containing only E7 phonemes. This difference resulted in a moderate to large effect size $(d=0.61)$. There were no significant differences between phoneme type for test phase $2(p=1.50)$ or test phase 3 $(p=0.758)$. These results suggest that learning differences occurred during test phase 1 as a result of phoneme type, but were not present during the recall of nonwords in test phases 2 and 3 . 
Table 4. Results from one-tailed paired-sample $t$-tests for the word learning task at each test phase (adapted from Moore, 2012).

\begin{tabular}{|c|c|c|c|}
\hline Test Phase & $\begin{array}{c}\text { E7 } \\
M(S D)\end{array}$ & $\begin{array}{c}\mathrm{L} 7 \\
M(S D)\end{array}$ & Test Statistics \\
\hline 1 & $57.84(13.01)$ & $49.32(15.19)$ & $\begin{array}{c}t(29)=3.86 \\
p<0.002^{*} \\
d=0.61\end{array}$ \\
\hline 2 & $23.70(15.45)$ & $23.70(14.60)$ & $\begin{array}{c}t(29)=0.00 \\
p=1.50 \\
d=0.00\end{array}$ \\
\hline 3 & $17.97(11.51)$ & $16.34(8.19)$ & $\begin{array}{c}t(28)=0.676 \\
p \leq 0.758 \\
d=0.17\end{array}$ \\
\hline
\end{tabular}

Note. Scores are reported as percentage of phonemes correct (PPC) for E7 and L7 stimuli in test phases 1,2 , and 3 . E7 = Early-7 stimuli; L7 = Late-7 stimuli; $d=$ Cohen's $d$. *Indicates significance at $p$, corrected for multiple comparisons

\section{Discussion}

Many studies have examined the role of phonological short-term memory in children with language impairments. One account of language impairment in children has suggested that the short-term memory storage capacity is reduced compared to their typical peers. This deficit is seen most prominently in children with language impairments during nonword repetition tasks, in which they have been found to score well below their typical peers. However, because nonword repetition relies on multiple processes such as long-term knowledge, phonological memory, auditory discrimination, articulation, etc. (Coady \& Evans, 2008; Graf-Estes et al, 2007; Moore, 2012), and because children with language impairment have also shown deficits in other aspects of language learning, e.g., long-term phonological knowledge and vocabulary acquisition (Bishop, 1997; Mainela-Arnold, Evans, \& Coady, 2008; Watkins, Kelly, Harbers, \& Hollis, 1995), other accounts of child language impairment have been explored. 
Few studies have experimentally examined the role of long-term knowledge on the learning of new words. The focus of this project was on the effects of long-term knowledge in learning new words by comparing recall accuracy of newly learned words containing only earlydeveloping sounds (E7) versus words containing only later-developing sounds (L7). It was predicted that recall accuracy would be lower for L7 words because of previous work that has suggested that the long-term phonological representation of the later-developing phonemes may be weaker in quality, and therefore would be more difficult to retrieve and/or utilize during a word-learning paradigm (Moore, 2012). Results showed recall differences at test phase 1 but not at test phases 2 and 3. This discussion first will offer an explanation of the results from the nonword repetition and the word learning tasks, and will discuss potential limitations to the current work as well as future directions for study. Finally, the implications for the current body of work in child language impairment will be reviewed.

\subsection{Nonword Repetition}

The nonword repetition task performed in this study replicated Moore's (2012) main findings in which nonwords comprising late-developing phonemes resulted in lower repetition accuracies than nonwords with early-developing phonemes at every syllable length. As expected, a main effect of syllable length in which nonwords containing more syllables generally resulted in decreased performance. Unlike Moore's study, in this study there was no significant interaction of phoneme type and syllable length. The difference in early-late phoneme (ELP) performance is greater in 4-syllable nonwords than at other syllable lengths, suggesting a trend toward an interaction, though this finding is not statistically significant.

The ELP effect was present during the nonword repetition task in this study using a new group of participants. It was stated in the introduction that nonword repetition is a skill that relies on multiple processes (Coady \& Evans, 2008; Graf-Estes et al, 2007; Moore, 2012), so one 
explanation for the ELP difference is that the presence of auditory perceptual and/or articulatory factors contributed to repetition differences. In this study there was no way to account for these factors, however, Moore carefully examined perceptual and articulatory differences using a process of elimination testing paradigm and found that the ELP effect persisted even after these factors were minimized or eliminated. Based on her previous findings and the similar pattern of results found in this current work, it is reasonable to conclude that these other possible factors cannot entirely explain the ELP difference observed during the nonword repetition performance in this study.

It is also important to note that the ELP effect cannot be explained entirely from limitations in the various processes of phonological short-term memory. A difference of about 78\% was found between repetition accuracies of E7 and L7 nonwords containing one, two, and three syllables, but $12 \%$ accuracy for the 4 -syllable nonwords. Findings in this study trend toward the pattern of an interaction: as syllable length increased to four syllables, the gap between repetition accuracy of E7 and L7 nonwords increased. Although the ELP effect seems to be exacerbated when phonological memory is taxed (i.e., when there is more information to repeat with longer nonwords), phonological short-term memory alone cannot account for the E7L7 differences. This is evident by the repetition differences between 1-syllable E7 and L7 items in which there were minimal demands on phonological short-term memory. This was further demonstrated in Moore's work when significant ELP effects were found during nonword reading and visual lexical decision tasks with 1-syllable stimuli in which words and nonwords were presented visually and remained on the screen until the participant responded. In the case of these visual-based tasks, there is little to no demand on short-term memory.

Because articulatory, perceptual, and short-term memory factors could not entirely 
account for the ELP effect, Moore hypothesized that the difference could lie within the various processes (e.g. storage or retrieval) of phonological long-term knowledge. According to this model, L7 phonemes have relatively weaker representations compared to E7 phonemes even within normal adults who are native speakers of English. Therefore, the ELP effect was used to measure the influence of the varied quality of phonological representations in the experimental word learning task.

\subsection{Word Learning}

The word learning task was designed to examine how long-term phonological knowledge contributes to learning new words. Results of the task indicated that E7 and L7 differences were present during the initial test phase, but were not present in test phases 2 or 3 . There are different ways to examine these findings. First, the overall performance in the word learning task will be discussed, followed by performance within test phases. Finally, long-term phonological knowledge contributions to these results in word learning will be identified.

\subsubsection{Overall word learning performance}

The average accuracy on the word learning task, across phoneme type and test phases, was $\sim 47 \%$. One explanation for the overall decreased performance was the high demands on the phonological short-term memory system due to the length of stimuli, number of stimuli, and the intermingling of target words with foils. As discussed in the previous section, multisyllabic words have been found to be much more difficult to repeat accurately than shorter words (Archibald \& Gathercole, 2007; Dollaghan \& Campbell, 1998; Graf-Estes et al, 2007; Moore, 2012). Participants were asked to repeat a total of 78 4-syllable nonwords during the task (72 foils and 6 target words). In this case, participants were not only challenged with longer nonwords, but a larger number of items to repeat, which likely fatigued the short-term memory system and made repeating and recalling the nonwords much more difficult. Additionally, the 
foils intermingled with the target words during the exposure trials contributed to the difficulty of learning the targets. Many participants, when asked to recall the name of the alien they learned, recalled one of the foil nonwords instead, or a target-foil hybrid. This confusion from one stimulus item to the next can be explained by echoic memory: the 'lingering' of auditory information after it's heard. Watkins and Watkins (1980) describe the effect of echoic memory when recalling a serial list in the auditory modality versus a visual modality: "modality effect refers to the higher level of recall of the last few items of a list when presentation is auditory as opposed to visual. It is usually attributed to echoic memory. The effect may be sharply reduced by an ostensibly irrelevant auditory item appended to the end of the list (p. 251)".

This fatigue of the phonological short-term memory system likely played a role in both the repetition of the stimuli as well as the learning of the target words. An important component of short-term memory (as depicted by Baddeley and colleagues) that facilitates learning new words is the phonological loop in which retention of verbal information over short periods of time is held within the phonological store, and rehearsed, to refresh decaying representations in the phonological store (Baddeley, Gathercole, \& Papagano, 1998). All of the factors discussed (i.e. length of stimuli, number of stimuli, and intermingling of foils) could impact word learning so that target words could not be rehearsed as effectively within short-term memory.

In summary, several factors related to task and stimulus design could have affected shortterm memory, which, in turn, could have resulted in low overall accuracy. There are two important points to note. First, the overall results from this task are similar to those found in the word learning task by Gupta (2003) from which this task paradigm was derived (recall accuracy was $\sim 46 \%$ ), indicating that the overall accuracy results are expectedly low. Second, none of the three factors discussed in this section differentially should affect E7 versus L7 stimuli. There 
were an equal number of target words for the E7 and L7 word lists and all of the stimuli were the same length. Further, the foils were balanced to account for the number of E7 and L7 phonemes within each foil.

\subsubsection{Overall test phase differences}

Test phase 1 was the only component of the word learning task that revealed a difference between recall of E7 nonwords and recall of L7 nonwords (see Table 4 in Results section 4.3). Various potential contributing factors have been identified to better understand why test phase 1 showed different results than test phases 2 and 3. These factors are related to differences in task design and learning load.

The experimental design in test phase 1 had several features that would have facilitated overall higher recall accuracies compared to test phases 2 and 3. In test phase 1, the participants learned two new words (i.e. alien names) in each target block using multiple exposures to wordobject pairings followed by immediate testing so that the time between exposure and recall was small and was the same for each set of aliens. During the test trials within a block, participants were only required to recall the two alien names within that block, one alien at a time, which decreased the learning load. Also, the array of images used during test phase 1 contained a total of four images, with only two images that were given names.

In contrast, test phases 2 and 3 had an entirely different experimental design in which there were no exposure trials, only test (i.e. recall) trials. An array of six aliens was shown and all six of the aliens had names the participants learned, which could have increased confusability between the six target names. Additionally, block order within test phase 1 seemed to affect the recall of alien names within test phases 2 and 3. There was a much longer lapse in time between test phase 1 block 1 and test phase 2 compared to the second and third blocks in test phase 1 and test phase 2 . 
Test phase 3 had the lowest overall accuracy of the three test phases. In addition to the aforementioned reasons for lower scores during test phases 2 and 3, participants' scores in test phase 3 could also be affected by the standardized measures that came after test phase 2: the CTOPP-2 subtests and the WRMT-III subtests. The CTOPP-2 included the Nonword Repetition subtest and the WRMT-III included the Word Attack (i.e. nonword reading) subtest, so that participants had more nonwords to repeat and read even though their phonological system was likely already fatigued from the experimental tasks. This could have impacted recall accuracy of the alien names in test phase 3.

All of these factors related to task design and learning load may have contributed to overall recall deficiencies in the later test phases, but there is no reason to suspect that these factors affected E7 and L7 stimuli differently. The experimental design was balanced so that neither phoneme type had an advantage in presentation order. Additionally, the CTOPP-2 and WRMT-III subtests should not have specifically affected either E7 or L7 recall.

\subsubsection{Long-term phonological knowledge influence on word learning}

The primary purpose of this study was to determine if long-term phonological knowledge impacted word learning in typical adults. At the onset of the study, it was predicted that L7 nonwords would be harder to learn than E7 nonwords. Results showed that the average L7 nonword recall accuracy was significantly lower than the recall accuracy for E7 nonwords during test phase 1 . The ELP contrast was used to operationalize the varied quality of phonological representations, suggesting that the storage and/or retrieval of long-term phonological memory (this study is not able to distinguish which subcomponents are involved) can affect a person's ability to learn new words. Phonological representations that are poorer in quality may result in poor word learning, storage, and recall. 
It was stated previously that the ELP contrast was used as a measure of long-term phonological knowledge because of the work previously conducted by Moore (2012) showing that the effect persisted in typical adults after accounting for other factors like short-term memory capacity and articulatory and perceptual demands by using a nonword reading task and lexical decision tasks. However, it is possible that these factors interact differently with the ELP contrast during a word learning task. Future studies could address these concerns by manipulating these factors using a similar process of elimination approach employed by Moore, only within a word learning paradigm. For example, future work could use only one-syllable nonword targets and foils in the word learning task. Using one-syllable stimuli would be less taxing for the short-term memory system. If the ELP effect persisted in this kind of task, it would suggest that phonological short-term memory alone cannot account for the ELP effect, strengthening the argument that the ELP effect represents the varied quality of long-term knowledge and its impact on word learning ability.

Another way to address the aforementioned concerns is to examine the ELP effect in word learning by 'eliminating' (or greatly minimizing) articulatory and perceptual influences on E7 and L7 stimuli. This could be done by employing a word learning task in which words are presented visually instead of auditorily, or responses are provided through a multiple choice keypress and measured for response time instead of measuring accuracy of spoken responses. If the ELP effect continued to persist within these word learning tasks, it again would further strengthen the hypothesis that the ELP contrast represents an underlying difference within the long-term phonological system which impacts word learning ability.

The ELP effect was found in test phase 1 of the word learning task, but if the ELP effect represents a difference of phonological representation quality, why was this effect not seen in 
test phases 2 or 3 ? Three possible explanations have been identified for the different results between test phases: overall poor word learning scores may have muted ELP differences in later test phases, there may not have been enough statistical power in test phases 2 and 3 to show a difference, or lexical retrieval may be different when learning versus retrieving information.

One explanation for why E7 and L7 nonword recall differences were not found in test phases 2 and 3 could be that there was a floor effect - i.e., the alien names were never properly learned in the first place, so that participants were less likely to recall accurately the names as time passed. Overall recall accuracy was much lower in test phases 2 and 3, which may favor this explanation (see Table 4 of Results section 4.3). A second explanation could be the potential lack of statistical power in test phases 2 and 3 . In test phase 1 , for each participant there were a total of 72 phonemes for each target nonword, thus 216 phonemes for each phoneme type. In test phase 2, as well as test phase 3, for each participant there were only 9 phonemes for each target, therefore a total of 27 phonemes for each phoneme type. The number of recall attempts for E7 and L7 phonemes was greatly reduced in test phases 2 and 3 as compared to test phase 1, which may have resulted in insufficient power for a statistically significant difference between phoneme types. In future work this could be addressed by presenting more opportunities to recall words by performing more test trials in one session, or over the course of multiple sessions, to increase the statistical power of the test phases 2 and 3.

Taking the lexical restructuring hypothesis into consideration, a third explanation is that early stages of word learning in adults involves more segmental (phoneme-level) processing which helps to create more holistic representations of the target words within long-term knowledge (Metsala et al, 2009). Results from this study may indicate that once a word is stored within long-term knowledge it requires less phonetic information to be retrieved. Thus, the 
phonetic variability in learning E7 or L7 nonwords may be diminished once the word has been learned and stored within long-term knowledge. One way to distinguish if the lack of an ELP effect in test phases 2 and 3 is a result of whole-word processing could be to complete a detailed response analysis of all test phases. This could help to determine if responses in each phase seem to be segmental in nature (random individual phonemes are correct) versus more holistic (larger 'chunks' are produced correctly within a word).

Another way to distinguish between these three explanations is to conduct another study in which overall recall accuracy is higher for all test phases in order to avoid potential floor effects. One way to increase overall recall accuracy could be to increase the amount of exposures a participant experiences with a target word. This could be done by increasing the amount of trials within test phase 1 , or by having the participants complete the word learning task more than once within a session or over several sessions. However, this approach to increasing overall accuracy could have a negative effect on overall learning if the additional training continues to fatigue the attention and phonological systems of the participants.

An alternative approach to increasing overall recall accuracy is to provide a more contextual-based word learning paradigm. The task in this current study employed a very explicit form of word learning: an object was shown and its name was provided over the course of continued exposure and test trials. This form of word learning is not natural in everyday contexts. Instead, the task could use more functional, contextual-based word learning strategies, such as teaching the nonword within a context of a story. According to the Lexical Quality Hypothesis, representations in long-term knowledge with complete sematic, orthographic, and phonological information are more efficient to retrieve (Perfetti \& Hart, 1985; 2002). Therefore 
providing context within a word learning task may create stronger phonological representations within long-term knowledge.

In summary, this study demonstrates the influence of long-term phonological knowledge on the ability to learn new words. Future work that varies other factors like short-term memory load, and articulatory and perceptual demands within the word-learning paradigm could strengthen the claims of the study. Furthermore, future work in examining recall performance in different phases of learning could provide insight to how long-term phonological knowledge may contribute differently at various stages of learning new words.

\subsection{Other considerations}

Two considerations to note about the experimental measures performed in this study. One potential concern that was discovered during testing was that the alien images used during the word learning task may have been somewhat familiar to two participants. The alien images were found using a basic internet search. After testing, two participants identified the alien images to be black and white sketches of cartoon characters from an animated television show called Ben 10. The show aired between December 2005 and April 2008. However, the television show was aimed toward children around the age of ten, whereas most of the participants in this study would have been older than the target audience for the show during the time the show was on air. These images were also different than the ones on the television show because these aliens were sketches in black and white with no visual background. Only 2 participants reported recognizing the alien images out of the 30 participants, and these participants' scores fall within the performance range for the entire group, suggesting that their modest information about the aliens did not impact their overall performance in either direction. Furthermore, it would not be expected that modest familiarity with the visual stimuli would favor either the E7 target words over the L7 target words, or vice versa. 
Another consideration in the study is the diverse dialectal differences found throughout the state of West Virginia. West Virginia University draws students from across the state in areas where different dialects of Standard American English are spoken: 20\% $(n=6)$ of subjects spoke with what the examiner judged to be West Virginia Appalachian dialects. Hamilton \& Hazen (2009) identified features of this dialect as the ungilding of the diphthong /aI/ (/bark/ to $/ \mathrm{bak} /)$, cluster reduction $(/ \operatorname{tr} \Lambda \mathrm{st} /$ to $/ \operatorname{tr} \Lambda \mathrm{s} /)$, final $/ \theta /$ deletion, $/ \mathrm{y} /$ variability (/tokıy/ to /tokın/), and /l/- vocalization (/kold/ to /ko:d). These dialectal differences may have played a role in the auditory perception of phonemes as well as the production of phonemes. Vowel pronunciations may have affected target word accuracy but would not have impacted consonant phonemes. Also clusters, /y/ sounds, or final $/ \theta /$ sounds were not present in target words of the word learning task. Therefore, the dialectal differences might have impacted overall performance on the experimental tasks, but would likely not have significantly impacted ELP recall differences.

\subsection{Implications}

Results from this study strengthen the claim that differences in the quality of phonological representations may be related to when individual speech sounds are acquired in development, with earlier-developing phonemes having more of an advantage in long-term knowledge than later-developing phonemes. Furthermore, the findings from the word learning task coupled with the persistent ELP effect in the nonword repetition task provide evidence to indicate that long-term knowledge is actively engaged in learning new words. In early stages of learning new words, long-term knowledge appears to apply already learned information through the contribution of phoneme-level, and possibly syllable-level, representations. This provides insight as to how the long-term memory system contributes to vocabulary and language learning 
and may have implications for future clinical and theoretical work with people who have language and reading impairments.

Although the current study was conducted with adults, it relates to the body of work that examines the phonological processing deficits in children with language and reading impairments. This study demonstrates some of the cognitive functions (namely, long-term phonological knowledge) that are utilized during word learning, so it is a reasonable extension to suggest that degraded phonological representations in children could be a contributing factor in their language deficits. In fact, although the leading explanation for the phonological processing deficits in children has been attributed to the various processes involved in short-term memory, research continues to uncover more than just short-term memory deficits during nonword repetition and other linguistic tasks in children with impairment (Archibald \& Gathercole, 2007; Gathercole, 2006; Moore, 2012; Rispens \& Baker, 2012). For example, Rispens and Baker (2012) compared results on nonword repetition, a short-term memory task (digit span), and tasks that examined phonological representations (word and nonword minimal pair discriminations) between children with SLI and/or reading impairments and children without impairments. The children with impairments were approximately 8 years old as well as a group of age matched peers; the language matched group was approximately 5 years old. Rispens and Baker found that age, group, short-term memory, and long-term phonological knowledge all played a significant role in the children's ability to repeat nonwords. In other words, long-term phonological knowledge is one factor that could affect performance on linguistic tasks. This is consistent with the findings from this current study and suggests that a deficit in long-term phonological knowledge could impair language ability. 
The tasks used to measure phonological representations were less predictive of nonword repetition performance in the older typically developing children in the Rispens and Baker study. This favors the lexical restructuring hypothesis, which was described above as one possible explanation for the ELP effect in test phase 1, but not in test phase 2 and 3, of this current study. As stated previously, the lexical restructuring hypothesis purports that, as children mature, they rely less on segments of words (i.e. phonemes and syllables) and more on holistic lexical knowledge to retrieve words form long-term knowledge (Metsala et al., 2009). The current study extends this hypothesis to suggest that, although there is a restructuring, the use of phonemelevel representations continues into adulthood and is utilized in early stages of learning complex new words.

There is potential clinical utility of the ELP contrast as a measure of long-term phonological knowledge. If children rely more on segmental representations (as claimed by the lexical restructuring hypothesis), it is plausible to hypothesize that the magnitude of the ELP effect would be greater in children. In which case, the ELP contrast could hold great diagnostic value when identifying children who have spoken language or reading impairments. Rispens and Baker (2012) suggested that short-term memory and phonological representations are “independently important for nonword repetition" (p. 691). Thus, it is reasonable to expect that the individual profiles of children with impairment could vary, such that they may have deficits in short-term memory processes, long-term phonological knowledge, or both. Because the ELP contrast is a within-subjects measure, paired with other tasks using a process of elimination approach described in Moore (2012), it might be possible to develop an individual profile for children with impairment. 
Establishing an individualized profile that can provide a differential diagnosis is not only useful for identifying deficits, but also can be used to identify strengths. Rispens and Baker's investigation showed that the children with only SLI or only reading impairment performed relatively better on the measures for phonological representations and the nonword repetition task, but performed as poorly as the SLI + reading impairment group on the short-term memory task. They suggested that perhaps the relative strength of phonological representations in children with either SLI or a reading impairment compensated for the poor short-term phonological memory capacity and helped to boost nonword repetition scores. Their findings support the claim of a "double deficit" of phonological short-term memory and long-term phonological knowledge in children with language and reading impairments (p. 691), again underscoring the importance of determining the relative contributions of these two processes within an individual.

The benefits of differentially diagnosing the strengths and weaknesses of short-term and long-term memory in children with language and reading impairment can have a great impact on intervention for these children as well. The idea that children with language impairments compensate for their short-term memory capacity deficit has been discussed throughout the literature (Gathercole, 2006). If children with language impairments have an area of strength within stored phonological knowledge, interventionists could capitalize on this strength by providing more effective treatment approaches that tap into their specified skill sets. Similarly, if some children with impairment have a profile in which phonological short-term memory is a relative strength and long-term phonological knowledge is a relative weakness, then different therapeutic approaches might be employed to best serve their needs. 


\section{Conclusion}

This study demonstrated the effect of long-term phonological knowledge in both nonword repetition and a word learning task when contrasting stimuli with early-developing versus late-developing phonemes. Nonwords containing only late-developing phonemes were repeated less accurately during the nonword repetition task and were more difficult to learn during the word learning task. Future studies that control for other potential factors could be conducted to strengthen these current findings. Exploring how words are learned within the typical mechanism provides insight as to where language learning may break down in children with language and reading impairments. Discovering the intricacies involved in word learning from the short-term memory mechanism, the long-term storage and retrieval process, and the word learning process can lead to great strides in diagnosing and treating these impairments. The ELP contrast in this study provides a novel within-subjects measure of long-term phonological knowledge, and has the potential to be used in future work to understand the theoretical constructs of language learning disabilities and how to effectively treat these disabilities. 


\section{Bibliography}

Anthony, J., Williams, J., Aghara, R. G., Dunkelberger, M. J., Novak, M., \& Mukherjee, A. (2010). Assessment of individual differences in phonological representation. Reading and Writing, 23, 969-994.

Archibald, L. M. D., \& Gathercole, S. E. (2007). Nonword repetition in specific language impairment: More than a phonological short-term memory deficit. Psychonomic Bulletin and Review, 14, 919-924.

Baddeley, A. D. (2001). Is working memory still working? American Psychologist, 56(11), 851864.

Baddeley, A. D., Gathercole, S. E., \& Papagno, C. (1998). The phonological loop as a language learning device. Psychological Review, 105, 158-173.

Baddeley, A. D., \& Hitch, G. J. (1974). Working Memory. In G. Bower (Ed.), The psychology of learning and motivation (Vol. 8, pp. 47-90).

Baddeley, A. D., \& Hitch, G. J. (2000). Development of working memory: should the PascualLeone and the Baddeley and Hitch models be merged? Journal of Experimental Child Psychology, 77(2), 128-137. doi: 10.1006/jecp.2000.2592

Bishop, D. V. M. (1997). Uncommon understanding: Development and Disorders of language comprehension in children. East Sussex, United Kingdom: Pscyhology Press.

Casalis, S., \& Louis-Alexandre, M. (2000). Morphological analysis, phonological analysis and learning to read French: a longitudinal study. Reading and Writing, 12(3), 303-335.

Claessen, M., \& Leitao, S. (2012). Phonological representation in children with SLI. Child Language Teaching and Therapy, 28(2), 211-233.

Coady, J. A., \& Evans, J. L. (2008). Uses and interpretations of non-word repetition tasks in children with and without specific language impairments (SLI). International Journal of Language \& Communication Disorders, 43(1), 1-40.

Dell, G. S. (1986). A spreading-activation theory of retrieval in sentence production. Psychological Review, 93(3), 283-321.

Dell, G. S. (1988). The retrieval of phonological forms in production: Tests of predictions from a connectionist model. Journal of Memory and Language, 27, 124-142.

Dickinson, D. K., \& Porche, M. V. (2011). Relation between language experiences in preschool classrooms and children's kindergarten and fourth-grade language and reading abilities. Child Dev, 82(3), 870-886. doi: 10.1111/j.1467-8624.2011.01576.x

Dollaghan, C. A. (1998). Spoken word recognition in children with and withou specific language impaimen. Applied Psycholinguistics, 19(2), 193-120.

Dollaghan, C. A., \& Campbell, T. (1998). Nonword repetition and child language impairment. Journal of Speech, Language, and Hearing Research, 41, 1136-1146.

Elbro, C., Borstrom, I., \& Petersen, D. K. (1998). Predicting dyselxia from kindergarten: The importance of distinctness of phonological representations of lexical items. Reading Research Quarterly, 33, 36-60.

Fowler, A. (1991). How early phonological development might set the stage for phoneme awareness. In: Brady S and Shankweiler D (eds) Phonological processes in literacy: A tribute to Isabelle Y. Liberman. Hillsdale, NJ: Lawrence Erlbaum Associates, 97-117.

Fowlert, A. E., \& Swainson, B. (2004). Relationships of naming skills to reading, memory, and receptive vocabulary: Evidence for imprecise phonological representations of words by poor readers. Annals of Dyslexia, 52(2), 247-220. 
Frisch, S. A., Large, N. R., \& Pisoni, D. B. (2000). Perception of wordlikeness: Effects of segment probability and length on processing of nonwords. Journal of Memory and Language, 42, 481-496.

Gathercole, S. E. (2006). Nonword repetition and word learning: The nature of the relationship. Applied Psycholinguistics, 27, 513-543.

Gathercole, S. E., \& Baddeley, A. D. (1989). Evaluation of the role of phonological STM in the development of vocabulary in children: A longitudinal study. Journal of Memory and Language, 28, 200-213.

Gathercole, S. E., \& Baddeley, A. (1989). Phonological memory deficits in language disordered children - is there a causal connection. Journal of Memory and Language, 29, 336 - 360.

Gathercole, S. E., \& Baddeley, A. D. (1990a). The role of phonological memory in vocabulary acquisition: A study of young children learning new names. British Journal of Psychology, 81, 439-454.

Gathercole, S. E., Frankish, C., Pickering, S. J., \& Peaker, S. (1999). Phonotactic influences on short term memory. Journal of Experimental Psychology: Learning, Memory, and Cognition, 25, 84-95.

Gathercole, S. E., Pickering, S. J.,Hall, M.,\&Peaker, S. J. (2001).Dissociable lexical and phonologicalinfluences on serial recognition and serial recall. Quarterly Journal of Experimental Psychology, 45A, 1-30.

Gathercole, S. E., Willis, C. S., Baddeley, A. D., \& Emslie, H. (1994). The Children's Test of Nonword Repetition: A test of phonological working memory. Memory, 2(2), 103-127.

Gathercole, S.E., Service, E., Hitch, G.J., Adams, A., and Martin, A.J. (1999). Phonological short-term memory and vocabulary development: Further evidence on the nature of the relationship. Applied Cognitive Psychology, 13, 65-77.

Gillon, G. (2002). Phonological Awareness intervention for children: From the research laboratory to the clinic. ASHA Leader, 7(22), 15-19.

Graf-Estes, K. G., Evans, J., \& Else-Quest, N. (2007). Differences in the nonword repetition performance of children with and without specific language impairment: A metaanalysis. Journal of Speech, Language, and Hearing Research, 50(1), 177-195.

Gupta, P. (2003). Examining the relationship between word learning, nonword repetition, and immediate serial recall in adults. The Quarterly Journal of Experimental Psychology, 56A(7), 1213-1236.

Gupta, P. (2005). Primacy and recency in nonword repetition. Memory, 13(3/4), 318-324.

Gupta, P., Lipinski, J., Abbs, B., \& Lin, P. (2005). Serial position effects in nonword repetition. Journal of Memory and Language, 53, 141-162.

Hamilton, S., \& Hazen, K. (2009). Dialect Research in Appalachia: A Family Case Study. West Virginia History: a Journal of Regional Studies, 3(1), 81-107.

Hester, E., \& Hodson, B. W. (2004). The role of phonological representation in decoding skills of young readers. Child Language Teaching and Therapy, 20(2), 115-133.

Hulme, C., Roodenrys, S., Schweickert, R., Brown, G. D. A., Martin, S., \& Stuart, G. (1997). Wordfrequency effects on short-term memory tasks: Evidence for a redintegration process in immediate serial recall. Journal of Experimental Psychology: Learning, Memory, and Cognition, 23,1217-1232.

Levelt, W. J. (2001). Spoken word production: A theory of lexical access. Proceedings of the National Academy of Science USA, 98(23), 13464-13471. doi: 10.1073/pnas.231459498 
Levelt, W. J., Roelofs, A., \& Meyer, A. S. (1999). A theory of lexical access in speech production. Behavioral and Brain Sciences, 22(1), 1-38; discussion 38-75.

Maillart, C., Schelstraete, M. A., \& Hupet, M. (2004). Phonological representations in children with SLI: a study of French. Journal of Speech Language. and Hearing Research, 47(1), 187-198. doi: 10.1044/1092-4388(2004/016)

Mainela-Arnold, E., Evans, J. L., \& Coady, J. A. (2008). Lexical representations in children with SLI: Evidence from a frequency-manipulated gating task. Journal of Speech Language and Hearing Research, 51(2), 381-393. doi: Doi 10.1044/1092-4388(2008/028)

Metsala, J.L., Stavrinos, D., \& Walley, A.C. (2009). Children's spoken word recognition and contributions to phonological awareness and nonword repetition: A one-year follow-up. Applied Psycholinguistics, 30, 101-121.

Moore, M. W. (2012). Differences between early-developing and late-developing phonemes in phonological processing (Doctoral Dissertation). University of Pittsburgh, Pittsurgh, Pennsylvania.

Moore, M. W., Tompkins, C. A., \& Dollaghan, C. A. (2010). Manipulating articulatory demands in nonword repetition: A "Late-8" nonword repetition task. Clinical Linguistics and Phonetics, 24(12), 997-1008.

Munson, B., Swenson, C. L., \& Manthei, S. C. (2005). Lexical and phonological organization in children: Evidence from repetition tasks. Journal of Speech, Language, and Hearing Research, 48, 108-124.

Muter, V., Hulme, C., Snowling, M. J., \& Stevenson, J. (2004). Phonemes, Rimes, Vocabulary, and Grammatical Skills as Foundations of Early Reading Development: Evidence From a Longitudinal Study. Developmental Psychology, 40(5), 665-681.

Perfetti, C. A. (1985). Reading Ability. New York: Oxford University Press.

Perfetti, C. A., \& Hart, L. (2002). The lexical quality hypothesis. In L. Verhoeven, C. Elbro \& P. Reitsma (Eds.), Studies in written language and literacy: Precursors of functionalliteracy. Amsterdam/Philadelphia: John Benjamins Publishing Company.

Rispens, J \& Baker, A. (2012). Nonword repetition: The relative contributions of phonological short-term memory and phonological representations in children with language and reading impairment. Journal of Speech, Language, and Hearing Research, 55. 683-694.

Roodenrys, S., Hulme, C., Lethbridge, A., Hinton, M., \& Nimmo, L. M. (2002). Word-frequency and phonological-neighborhood effects on verbal short-term memory. Journal of Experimental Psychology: Learning, Memory, and Cognition, 28(6), 1019-1034.

Schneider, W., Eschman, A., \& Zuccolotto, A. (2002). E-Prime reference guide. Pittsburgh: Psychology Software Tools Inc.

Schweikert, R. (1993). A multinomial processing tree model for degradation and redintegration in immediate recall. Memory and Cognition, 21, 168-175.

Shriberg, L. D. (1993). Four new speech and prosody-voice measures for genetics research and other studies in developmental phonological disorders. Journal of Speech and Hearing Research, 36, 105-140.

Shriberg, L. D., \& Kwiatkowski, J. (1994). Developmental phonological disorders I: A clinical profile. Journal of Speech and Hearing Research, 37, 1100-1126.

Snowling, M. J., \& Hulme, C. (1994). Philosophical transactions: Biological sciences. The Aquisition and Dissolution of Language, 346(1315), 21-27. 
Thorn, A. S. C., Gathercole, S. E., \& Frankish, C. R. (2005). Redintegration and the benefits of long-term knowledge in verbal short-term memory: An evaluation of Schweikert's (1993) multinomial processing tree model. Cognitive Psychology, 50, 133-158.

Ullman, M.T. and Gopnik, M. (1994) The production of inflectional morphology in hereditary specific language impairment. In The McGill Working Papers in Linguistics: Linguistic Aspects of Familial Language Impairment (Vol. 10)(Matthews, J., ed.), pp. 81-118, McGill University

Ullman, M. T., \& Pierpont, E. I. (2005). Specific language impairment is not specific to language: the procedural deficit hypothesis. Cortex, 41(3), 399-433.

Wagner, R. Torgesen, J., \& Rashotte, C. (1999). Comprehensive Test of Phonological Processing. Pearson.

Walker, D., Greenwood, C., Hart, B., \& Carta, J. (1994). Prediction of school outcomes based on early language production and socioeconomic factors. Child Development, 65, 606-621.

Watkins, O. C., \& Watkins, M. J. (1980). The modality effect and echoic persistence. Journal of Experimental Psychology: General, 109(3), 251-278.

Watkins, R., Kelly, D., Harbers, H., \& Hollis, W. (1995). Measuring children's lexical diversity: Differentiating typical and impaired language learners. Journal of Speech and Hearing Research, 38, 1349-1355.

Woodcock, R. (2011). Woodcock Reading Mastery Test- III. Pearson.

Wolf, M., Vellutino, F., \& Berko Gleason, J. (1998). A psycholinguistic account of reading. In J. Berko Gleason \& N. Bernstein Ratner (Eds.), Psycholinguistics (2nd ed.). Fort Worth, TX: Harcourt Brace College Publishers.

Vitevitch, M., \& Luce, P. (1998). When words compete: Levels of processing in perception of spoken words. Psychological Science, 9, 325-329.

Vitevitch, M., \& Luce, P. (1999). Probabilistic phonotactics and neighborhood activation in spoken word recognition. Journal of Memory and Language, 40, 374-408. 